US Army Corps

of Engineers $s_{\circledast}$

Engineer Research and

Development Center

\title{
Isarithmic Mapping of Radio-Frequency Noise in the Urban Environment
}

Caitlin E. Haedrich, Daniel J. Breton, D. Keith Wilson

August 2020

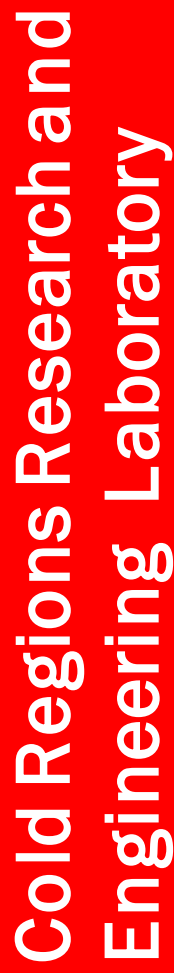


The U.S. Army Engineer Research and Development Center (ERDC) solves the nation's toughest engineering and environmental challenges. ERDC develops innovative solutions in civil and military engineering, geospatial sciences, water resources, and environmental sciences for the Army, the Department of Defense, civilian agencies, and our nation's public good. Find out more at www.erdc.usace.army.mil.

To search for other technical reports published by ERDC, visit the ERDC online library at https://erdclibrary.on.worldcat.org/discovery. 


\title{
Isarithmic Mapping of Radio-Frequency Noise in the Urban Environment
}

\author{
Caitlin E. Haedrich, Daniel J. Breton, D. Keith Wilson
}

Cold Regions Research and Engineering Laboratory

U.S. Army Engineer Research and Development Center

72 Lyme Road

Hanover, $\mathrm{NH} 03712$

Final report

Approved for public release; distribution is unlimited.

\footnotetext{
Prepared for U.S. Army Corps of Engineers

Washington, DC 20314

Under Program Element 0611102T, Project Number T442, and Task Number 01
} 


\section{Preface}

This study was conducted for the U.S. Army Corps of Engineers under Program Element 0611102T, Project T442, and Task Number 01. The Technical monitor was Dr. Marino A. Niccolai.

The work was performed by the Signature Physics Branch of the Research and Engineering Division, U.S. Army Engineer Research and Development Center, Cold Regions Research and Engineering Laboratory (ERDCCRREL). At the time of publication, Mr. Dr. Marino A. Niccolai was Branch Chief; Mr. James Horne was Division Chief; and Dr. Robert Davis was the Technical Director for Geospatial Research and Engineering. The Deputy Director of ERDC-CRREL was Mr. David B. Ringelberg, and the Director was Dr. Joseph L. Corriveau.

This paper was originally published in proceedings of the Military Sensing Symposium 2019, held February 25 - 28, 2019 in Orlando, FL. Funding was provided by the US Army Basic Research Program.

The Commander of ERDC was COL Teresa A. Schlosser and the Director was Dr. David W. Pittman. 


\title{
Isarithmic mapping of radio-frequency noise in the urban environment
}

\begin{abstract}
Radio-frequency (RF) background noise is a spatially-varying and critical parameter for predicting radio communication system and electromagnetic sensor performance in urban environments. Previous studies have measured urban RF noise at fixed, representative locations. The Cold Regions Research and Engineering Laboratory (CRREL) has developed a tunable system for conducting mobile RF noise measurements in the VHF and UHF and shown that urban RF noise characteristics vary significantly and repeatably at a scale of tens of meters (Haedrich \& Breton, 2019). CRREL also found high-powered regions in Boston, MA that are persistent over time. However, since previous studies conducted stationary measurements or measurements along linear transects, little is known about the 2-dimensional topography of urban noise and the spatial distribution and characteristics of these high-powered regions. In this paper, we present the results of a dense, block-grid survey of downtown Boston, MA at 142 and $246.5 \mathrm{MHz}$ with measurements taken every meter along each street. We present isarithmic maps of median noise power and describe the spatial distribution, shape and other characteristics of the high-powered regions. We compare the rate of noise power decay around high-powered regions to losses predicted by a power law model of path loss.
\end{abstract}




\subsection{Introduction}

Radio-frequency (RF) background noise is a spatially-varying and critical parameter for predicting radio communication and electromagnetic sensor system performance in urban environments. High levels of RF noise can degrade RF system performance by decreasing intelligibility, increasing bit-error rates, and decreasing sensitivity while increasing false alarm rates in analog voice, digital, and sensing systems respectively. Therefore, accurate measurements of noise power and its variability throughout the urban environment are necessary to support military and first responder operations in the commonly used VHF and UHF bands.

RF noise comes from many different sources, both man-made and natural. Natural noise such as galactic and atmospheric sources are most powerful in the HF and VHF ranges (ITU, 2016). At frequencies typically used for communications by military and first responders in the high VHF to UHF, natural noise is low in power (ITU, 2016). Above $30 \mathrm{MHz}$, man-made noise typically dominates natural noise even in rural settings (Leferink, et al., 2010).

Modern man-made RF noise consists of unintentional emissions from sources such as electronic devices, power transmission lines, and internal combustion engine ignitions (ITU, 2016). Electronic devices such as cellular phones, wireless internet routers and printers are relevant to the urban noise field because of their increasing pervasiveness in urban environments over the last decade.

Significant work has been done to measure and characterize VHF man-made noise levels in urban environments over the last 60 years (Skomal, 1965; Buehler, King, \& Lunden, 1968; Middleton, 1973; Parsons \& Sheikh, 1981; Fockens, Zwamborn, \& Leferink, 2019; Herman, 1969; Lauber \& Bertrand, 1977; Skomal, 1973). The large majority of these studies have focused on stationary, fixed location measurements taken over the course of hours and days at locations deemed representative of an area use class (Esposito \& Buck, 1973; Achatz \& Dalke, 2001; Wagstaff \& Merricks, 2005; Wepman \& Sanders, 2011; Achatz, Lo, Papazian, Dalke, \& Hufford, 1998; Dalke, Achatz, Lo, Papazian, \& Hufford, 1997). Several studies have conducted airborne measurements to capture variability over a city (Skomal, 1969; Skomal, 1970; Roy, 1981; Cudak, Swenson, \& Cochran, 1991). The scale of these observations is on the scale of kilometers, showing the largest noise powers in the downtown and decreasing as one moves away from the city center. Skomal (1970) reports a path loss exponent of 1.8 as distance increases in frequency bands between 150 and $500 \mathrm{MHz}$.

Of particular relevance to this study is the work of Spaulding et al. (1971) who conducted noise measurements at $48 \mathrm{MHz}$ while driving through San Antonio, Texas. Spaulding et al. (1971) showed manmade noise can vary significantly ( $15 \mathrm{~dB}$ at the city-block scale) and correlated this variability to vehicle and traffic density.

The work of Spaulding et al. (1971) along with the extensive fixed-location surveys of Spaulding and Disney (1974) became the foundation for the International Telecommunications Union's (ITU) model for noise (ITU-R 372) (ITU, 2016) which predicts median noise levels and noise level variability in urban, residential, rural and quiet rural environments at frequencies below $250 \mathrm{MHz}$. This model is still the international standard for predicting noise levels in urban environments.

Since the development of the ITU model (ITU, 2016) and the work of Spaulding and Disney (1974), the urban noise field has evolved significantly (Wepman \& Sanders, 2011; Haedrich \& Breton, 2019). In previous work, the Cold Regions Research and Engineering Laboratory (CRREL) developed a mobile, tunable noise measurement backpack and deployed the system in Boston, MA (Haedrich \& Breton, 2019). Measurements were collected every meter along transects though two neighborhoods at $142 \mathrm{MHz}, 246.5$ $\mathrm{MHz}$ and $972 \mathrm{MHz}$. Haedrich and Breton (2019) found that median noise power can vary up to $30 \mathrm{~dB}$ over several blocks in a dense urban environment and that this variability is spatially consistent over time. Contrary to the symmetric variability predicted by the ITU-R 372 model, they also found the distribution 
of median power values were heavy-tailed resulting from the presence of several high-powered regions that were in excess of $10 \mathrm{~dB}$ above the overall median.

Since previous studies conducted stationary measurements or measurements along linear transects through the urban environment, little is known about 2-dimensional topography of urban noise and the spatial distribution and characteristics of the high-powered regions found in previous work. In this paper, we expand on CRREL's previous work (Haedrich \& Breton, 2019) with a dense, block-grid VHF and UHF noise survey over a $0.15 \mathrm{~km}^{2}$ area of downtown Boston, MA. These dense surveys allow us to address questions about the fundamental nature of urban man-made noise and its impact on military and first responder communications. Is the urban noise field dominated by several high power sources or by distributed low-power sources? How far apart are these high-powered regions? How quickly do power levels decay as one moves away from a high-powered region?

\subsection{Methods}

We deployed CRREL's mobile noise measurement system in downtown Boston, MA to conduct a dense, block-grid survey of RF noise. Details and specifications for the system can be found in Haedrich and Breton (2019). Below, we provide an overview of the system and our survey methodologies.

\subsection{Mobile Measurement System}

The mobile noise measurement system developed at CRREL is a backpack-mounted system meant to be operated by a team of two. We record measurements on foot because we can reach locations inaccessible by cars such as park walkways, small alleys and pedestrian only streets. The backpack design also eliminates the possibility of vehicle noise contamination that could occur if the system were vehiclebased.

Conducting measurements in deep urban canyons presents geolocation challenges. Tall buildings reflect and scatter GPS signal resulting in poor or no GPS reception (Paulson, 2019). To mitigate this, we use a 1-meter measuring wheel to record our progress along a pre-determined route. The wheel triggers a measurement with each full rotation, enabling geolocation for each of the measurements by interpolating its location along the pre-determined route.

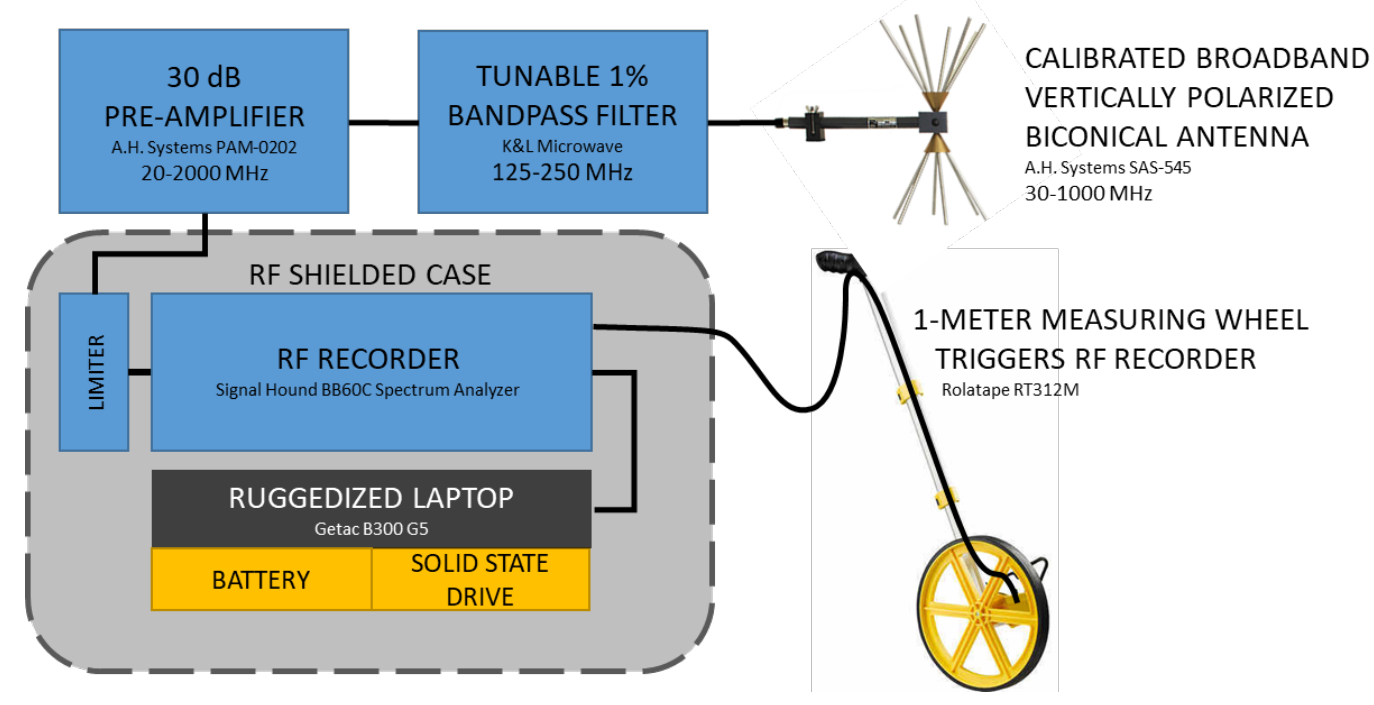

Figure 1. Schema of the mobile noise measurement system. 
We use a calibrated broadband vertically polarized biconical antenna (A.H. Systems SAS-545) which is fed to a tunable $1 \%$ bandpass filter (K\&L Microwave, 5BT-125/250-1-N/N) for preselection. This preselection filter is critical to the systems performance because strong out-of-band emissions, especially after amplification, can overload the RF recorder's ADC and lead to spurious signals within the bandwidth of interest. The filtered noise is passed to a broadband $30 \mathrm{~dB}$ Pre-Amplifier (A.H. System PAM-0202) powered by a 12V lead-acid battery. The Pre-Amplifier ensures the measured external noise power is greater than the RF recorder's internal noise. The noise signal is fed into an RF shielded case that houses the RF recorder (Signal Hound Spectrum Analyzer BB60C) and laptop computer (Getac B300GS). Our laboratory work has shown that our computer (like most computers) produces measurable amounts of RF noise. The shielded case prevents this noise from reaching the biconical antenna and contaminating our measurements.

The laptop computer interfaces with the RF recorder with a USB 3.0 cable and Signal Hound's Spike software. The software is set to collect a $250 \mathrm{~ms}$ recording of in-phase and quadrature (I and Q) data in a $1 \mathrm{MHz}$ effective bandwidth every time it receives a signal from the measuring wheel. The laptop computer has a solid state drive allowing for fast write speeds to accommodate recording I and Q data. A fully charged laptop battery allows the system to operate for 4 hours. We carry additional laptop batteries that can be swapped in to extend the system's operation time.

To calibrate the system and determine our internal noise figures, we used the Y-Factor method described in Keysight Technologies (2018) with a calibrated diode noise source (Fairview Microwave FMNG1021). The Signal Hound Spike software has multiple sensitivity settings, called reference levels. In previous work, we found that our measurements at $142 \mathrm{MHz}$ occasionally exceeded the dynamic range of the system while set to a reference level of $-40 \mathrm{dBm}$ (Haedrich and Breton, 2019). To mitigate this, we conducted repeat surveys with a reference level of $-40 \mathrm{dBm}$ and $-30 \mathrm{dBm}$. Table 1 contains the noise figures for each reference level and frequency.

Table 1. System sensitivity and noise figures for the measurement system.

\begin{tabular}{cccccc}
\hline \multicolumn{7}{c}{$\mathbf{1 4 2} \mathbf{~ M H z}$} \\
\hline Reference Level & $\begin{array}{c}\text { Noise Figure } \\
(\mathrm{dB})\end{array}$ & $\begin{array}{c}\text { Overall Gain } \\
(\mathrm{dB})\end{array}$ & $\begin{array}{c}\text { Min. Detectable } \\
\text { Power }(\mathrm{dBm})\end{array}$ & $\begin{array}{c}\text { Max. Detectable } \\
\text { Power }(\mathrm{dBm})\end{array}$ & $\begin{array}{c}\text { Antenna Gain } \\
(\mathrm{dBi})\end{array}$ \\
\hline $\mathbf{- 3 0} \mathbf{~ d b m}$ & 8.7 & 17.5 & -104.4 & -46.1 & -9.3 \\
$\mathbf{- 4 0 ~ d B m ~}$ & 7.9 & 17.8 & -105.3 & -56.4 & -9.3 \\
& & & & & \\
\hline
\end{tabular}

246.5 MHz

\begin{tabular}{cccccc}
\hline Reference Level & $\begin{array}{c}\text { Noise Figure } \\
(\mathrm{dB})\end{array}$ & $\begin{array}{c}\text { Overall Gain } \\
(\mathrm{dB})\end{array}$ & $\begin{array}{c}\text { Min. Detectable } \\
\text { Power }(\mathrm{dBm})\end{array}$ & $\begin{array}{c}\text { Max. Detectable } \\
\text { Power }(\mathrm{dBm})\end{array}$ & $\begin{array}{c}\text { Antenna Gain } \\
(\mathrm{dBi})\end{array}$ \\
\hline $\mathbf{- 4 0 ~ d B m}$ & 7.0 & 30.7 & -106.1 & -69.2 & 2.7
\end{tabular}




\subsection{Survey Location and Methods}

Downtown Boston features densely-spaced, high-rise buildings primarily used as office space and some as hotels and residences. There are several green spaces in our survey area: the Rose Kennedy Greenway runs along the eastern edge of downtown, Post Office Square is adjacent to Congress Street and Winthrop Square is on Otis Street (Figure 2). Between Winthrop Square and Federal Street, a large construction site takes up most of the block. The construction site had large machinery such as cranes, generators, and large bore drills. Most streets are narrow with two to three lanes of traffic at a minimum width of 10 feet per lane (Boston Transportation Department, 2013). Interstate 93 runs in a tunnel underneath the Greenway.

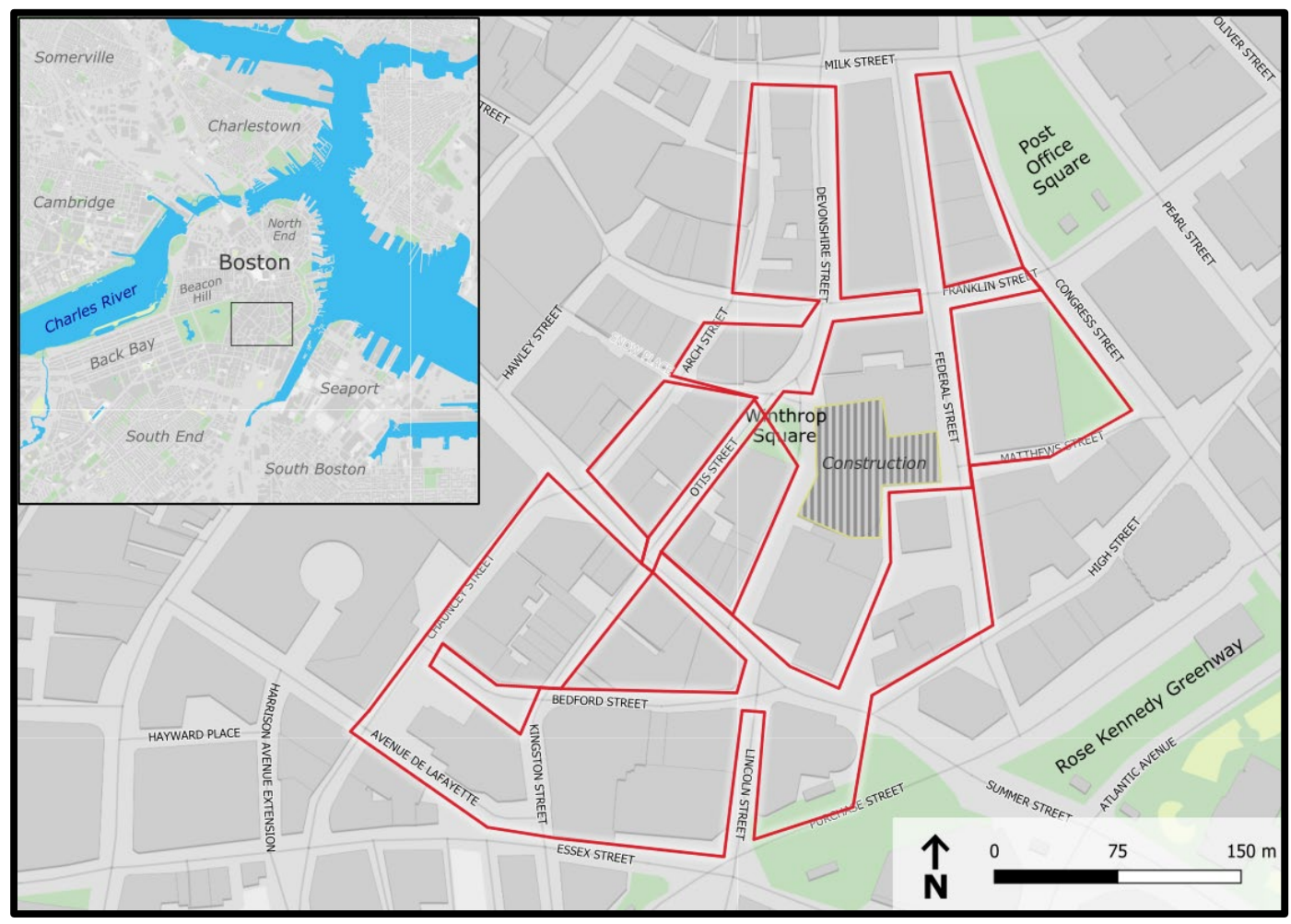

Figure 2. Map of survey area and route through downtown Boston, MA, USA. (Background map: (C) OpenStreetMap contributors.)

During previous fieldwork, we found $1 \mathrm{MHz}$ bandwidths centered on 142 and $246.5 \mathrm{MHz}$ that were free of intentional emissions and had no strong emitters in immediately adjacent frequencies (Haedrich \& Breton, 2019). We confirmed this was the still the case in July of 2019, by conducting a brief spectrum survey before beginning our measurements.

We selected a route through downtown that covered every accessible street and alley over several blocks. The route is approximately $4 \mathrm{~km}$ long, covers $0.15 \mathrm{~km}^{2}$, and takes just under 2 hours to walk with the measurement system (Figure 2). We conducted all of our measurements during normal business hours on weekdays. In previous work in downtown Boston, we found that spatial patterns in median noise power were consistent over time (Haedrich \& Breton, 2019) so, for this work, we considered one survey sufficient to describe the spatial variability of noise power. 


\subsection{Results}

We conducted surveys at 142 and $245.5 \mathrm{MHz}$ during the afternoon of Tuesday, July $16^{\text {th }}$ and during business hours on July $17^{\text {th }}, 2019$. A team of two researchers traversed the route; one person carried the backpack and measuring wheel while the other took notes and carried extra batteries, tools and spare supplies. The second person also recorded the distance traveled between control points along the route (corners, intersections, etc.) so that the collected data could be geolocated afterwards.

At $142 \mathrm{MHz}$, we repeated the route with two different sensitivity levels. During the more sensitive survey (reference level $-40 \mathrm{dBm}$ ), measurements in the high-powered regions often exceeded the maximum measurable power (see Table 1). In these areas, we substituted the nearest measurement taken during the less sensitive survey (reference level $-30 \mathrm{dBm}$ ) to create one dataset. Histograms for the 246.5 and combined-sensitivity $142 \mathrm{MHz}$ measurements are found in Figure 3 with associated statistics in Table 2.
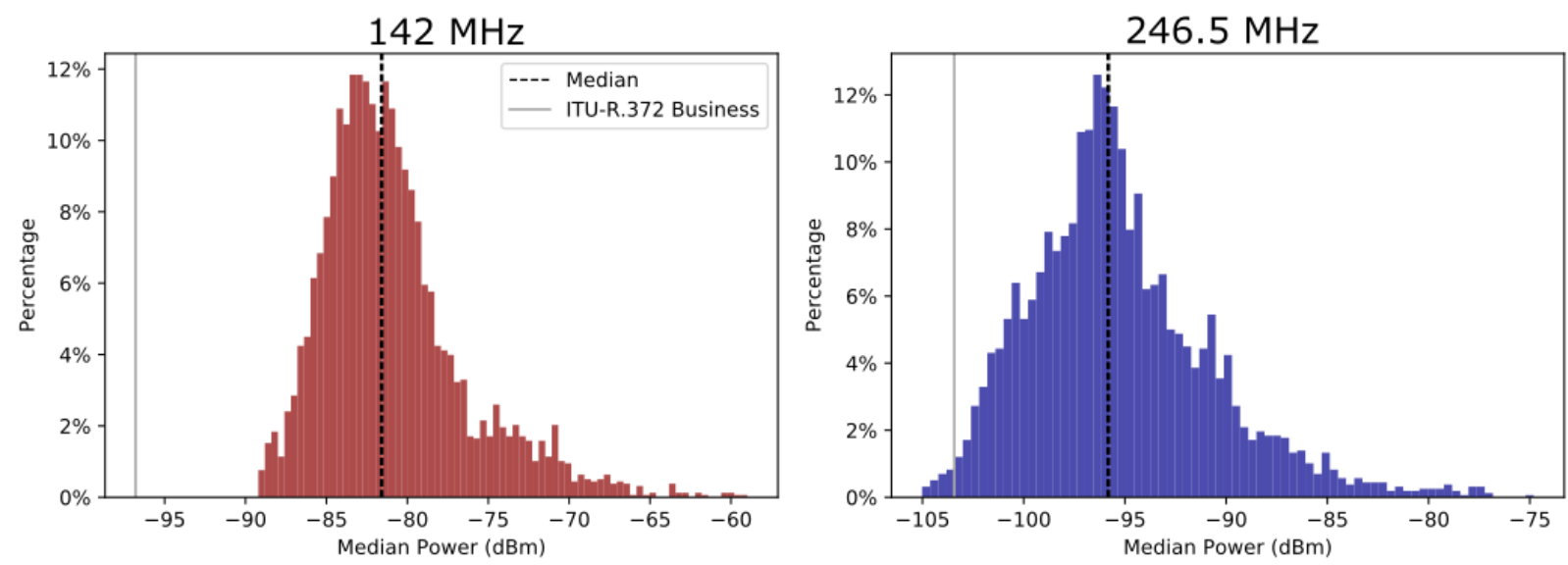

Figure 3. Histograms showing the distribution of median external noise power measured every meter along the whole route for the $142 \mathrm{MHz}$ (left, red) and 246.5 MHz (right, blue) bands.

Table 2. Descriptive statistics for the distribution of median powers collected in the 142 and 246.5 MHz surveys.

\begin{tabular}{cccccc}
\hline $\begin{array}{c}\text { Frequency } \\
(\mathbf{M H z})\end{array}$ & Median (dBm) & $\begin{array}{c}\text { Minimum } \\
\mathbf{( d B m )}\end{array}$ & $\begin{array}{c}\text { Maximum } \\
\mathbf{( d B m})\end{array}$ & Range (dB) & $\begin{array}{c}\text { Std. Deviation } \\
(\mathbf{d B})\end{array}$ \\
\hline $\mathbf{1 4 2}$ & -81.6 & -89.2 & -58.9 & 30.2 & 4.4 \\
$\mathbf{2 4 6 . 5}$ & -95.9 & -105.0 & -74.8 & 30.2 & 4.5
\end{tabular}

From our point data, we created isarithmic maps of median power using a spline algorithm. Isarithmic maps (often colloquially called "heat maps") are a type of thematic map used to represent a continuous data field. For example, a topographic map is an isarithmic map that shows elevation. To reduce the impact of temporal variations and smooth data, we grouped measurements in 10-meter segments before splining. We used the QGIS GRASS v.surf.bspline tool (GRASS Development Team, 2019) with the bilinear interpolation algorithm, a step of 8 meters and an output pixel size of 1 meter. The resulting maps are found in Figure $4(142 \mathrm{MHz})$ and Figure $5(246.5 \mathrm{MHz})$. 


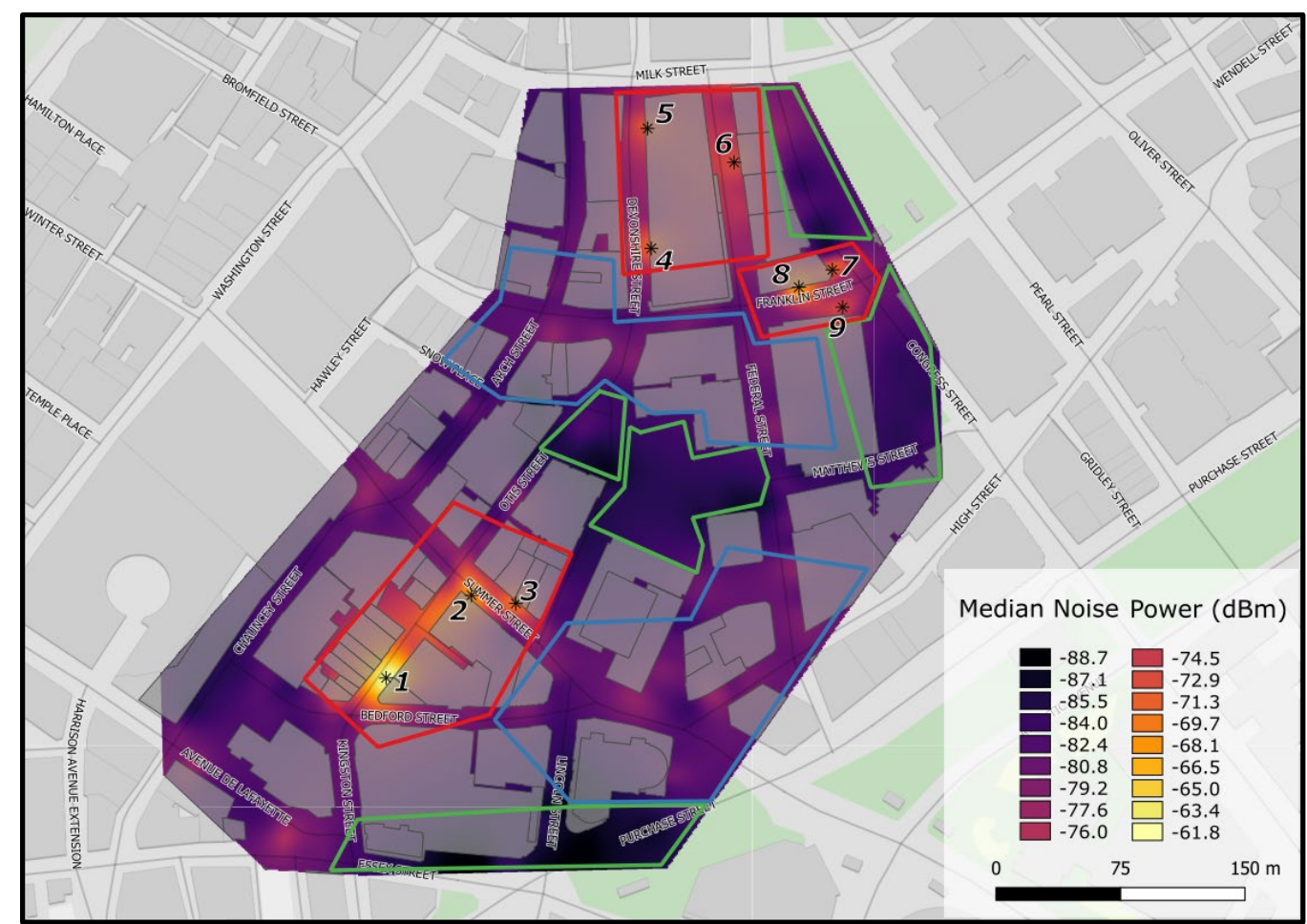

Figure 4. Map of Median Noise Power at $142 \mathrm{MHz}$ in downtown Boston, MA. Local maxima in the upper decile of the measurements are marked and labeled. Region types outlined for Discussion Section (red: point source dominated, blue: distributed sources, green: open spaces). (Background map: (C) OpenStreetMap contributors.)

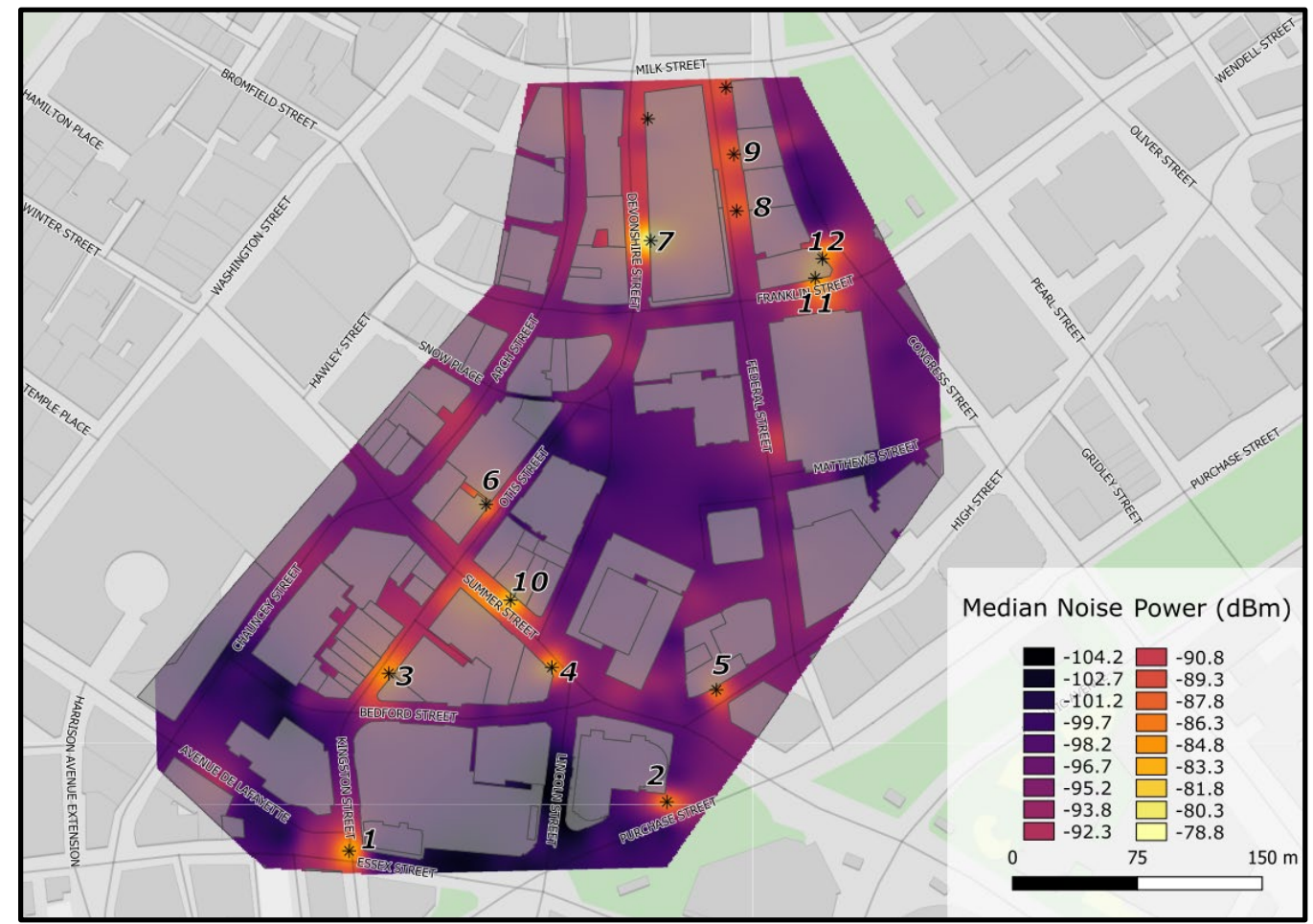

Figure 5. Map of Median Noise Power at 246.5 MHz in downtown Boston, MA. Local maxima in the upper decile of the measurements are marked and labeled. (Background map: (C) OpenStreetMap contributors.) 


\subsection{Discussion}

Our goal was to characterize the 2-dimensional topography of the urban noise field and to describe the spatial distribution of high-powered regions found in previous work. We accomplished this by surveying a dense grid of streets in downtown Boston, MA and creating isarithmic maps of median noise power. Like Haedrich and Breton (2019), we found significant variability in the urban noise field and found many high-powered regions throughout downtown Boston, MA. Median noise power varied over $30 \mathrm{~dB}$ depending on frequency and location. We divide our discussion into 3 sections: (1) discussion of the spatial distribution of noise, (2) comparison of results to previous work in Boston, MA and (3) discussion on the nature of urban noise sources and the application of a power law model.

\subsection{Spatial Distribution of Noise}

The isarithmic maps suggest that Boston's downtown can be divided into three categories of RF noise: (1) areas dominated by a few high-powered point sources, (2) areas with many distributed, low-power noise sources and (3) open areas with few noise sources. These high-powered sources are likely near the local maxima marked with an asterisk in Figure 4 and Figure 5. Areas with many low-powered sources result in slowly undulating noise powers like those found on Arch Street. Open areas, like parks and construction sites, have low values, as they are unlikely to contain many noise sources.

There are differences in the distribution and characteristics of high-powered local maxima between 142 and $246.5 \mathrm{MHz}$ (Figure 4 and Figure 5). There are more local maxima at $246.5 \mathrm{MHz}$ than at $142 \mathrm{MHz}$ with 14 and 9 points, respectively. Additionally, at $142 \mathrm{MHz}$, the average distance to the nearest neighboring maximum point is 41 meters, while at $246.5 \mathrm{MHz}$, the average distance is 52 meters, indicating that there is more clustering of sources at 142 than $246.5 \mathrm{MHz}$.

By selecting representative areas (shown in Figure 4) of each of these types at $142 \mathrm{MHz}$ (point source dominated, distributed sources and open space/few sources), we generalize the noise power behavior in Table 3. Areas with point sources have the largest range and highest median power, while open spaces and areas with distributed sources have the smaller ranges. Compared to open spaces, areas with distributed sources have higher median values because of the close proximity to sources.

Table 3. Average median and range of noise power by region at $142 \mathrm{MHz}$. Representative regions are outlined in Figure 4.

\begin{tabular}{lcccc}
\hline \multicolumn{1}{c}{ Region Type } & $\begin{array}{c}\text { Average Median } \\
\text { Power } \mathbf{( d B m )}\end{array}$ & $\begin{array}{c}\text { Standard } \\
\text { Deviation (dB) }\end{array}$ & Range (dB) & $\begin{array}{c}\text { Total Area of } \\
\text { Region }\left(\mathbf{m}^{2}\right)\end{array}$ \\
\hline $\begin{array}{l}\text { Buildings, dominated } \\
\text { by point sources }\end{array}$ & -76.3 & 3.1 & 23.4 & 46201.5 \\
$\begin{array}{l}\text { Buildings, distributed } \\
\text { sources }\end{array}$ & -81.4 & 1.4 & 9.8 & 61673.0 \\
$\begin{array}{l}\text { Open Space (parks, } \\
\text { construction site, etc.) }\end{array}$ & -84.3 & 1.4 & 12.0 & 40361.8
\end{tabular}

\subsection{Comparison to Previous Work}

Our measurements for this work were $14.8 \mathrm{~dB}$ and $7.5 \mathrm{~dB}$ above the predicted median noise powers of the ITU-R 372 city model for 142 and $246.5 \mathrm{MHz}$, respectively (ITU, 2016). Comparisons of our earlier measurements with the ITU-R 372 model and with the literature can be found in Haedrich and Breton (2019). Therefore, in this section, we will compare our results to those collected in 2018 by Haedrich and Breton (2019). 
Our overall median was 6.5 and $2 \mathrm{~dB}$ higher at 142 and $246.5 \mathrm{MHz}$ respectively than the 2018 data. The higher medians can be attributed to a new route; last year, our route included significantly more space. Additionally, we found similar values and variability along the overlapping sections of the routes and consistent locations of high-powered regions. In 2018, we observed high-powered regions along Devonshire Street (near points 4 and 5 for $142 \mathrm{MHz}$ and point 7 for $246.5 \mathrm{MHz}$ ) and at the corner of Kingston and Bedford (near point 1). We also found spatial agreement in locations of the lowest median values; parks and open places (such as The Greenway, Winthrop Square and Post Office Square) consistently have values in the lower quartile of our data. Interestingly, even with heavy machinery present, the construction site between Devonshire and Federal Streets had median values comparable with parks.

\subsection{Urban Noise Sources and the Power Law Model}

Since high-powered regions are likely to have the greatest impact on spectrum users, characterizing the shape and power-decay rate around these regions is useful. We hypothesize that these high-powered regions results from a point-like source. To support this hypothesis, we compare transects over the local maxima with a power law model for point-source signal propagation. To make this comparison, we assume that our 10-meter data spacing provides adequate spatial resolution to resolve the shape of these high-powered regions.

Both theoretical and empirical propagation models show that the average received signal power in linear units decreases logarithmically with distance to the transmitter (Rappaport, 2002). Thus, the received power, $p_{r}$, is proportional to distance, $d$, and some path loss exponent, $n$ :

$$
p_{r} \propto \frac{1}{d^{n}}
$$

The value of $n$ is dependent on the environment and has been the subject of extensive research (Bertoni, 2000). For free space path loss, $n$ is equal to 2 . As the number of obstructions within the environment increases, $n$ generally increases, though cases have been observed where wave-guiding effects within urban canyons lead to $n$ values less than 2. Rappaport (2002) reports typical $n$ values between 2.7 and 3.5 for urban cellular radio. However, free space path loss $(n=2)$ is likely an adequate assumption for our purposes since the distances over which these high-powered regions occur are small.

Since the exact noise source locations and emission powers are unknown in our dataset, we adapt the equation above for a scenario where we walk past a point source that is $b$ meters from our path. Let $a$ be the distance from the local maximum to the receiver as shown in Figure 6. Then, the power received will be proportional to:

$$
p_{r} \propto \frac{1}{\left(\sqrt{a^{2}+b^{2}}\right)^{2}}
$$

We fit this model to using extracted profiles over each maximum identified by asterisks in Figure 4 and Figure 5. The best-fit value of $a$ provides an estimate of the distance from our path to the assumed pointlike noise source (Figure 7 and Figure 8). 


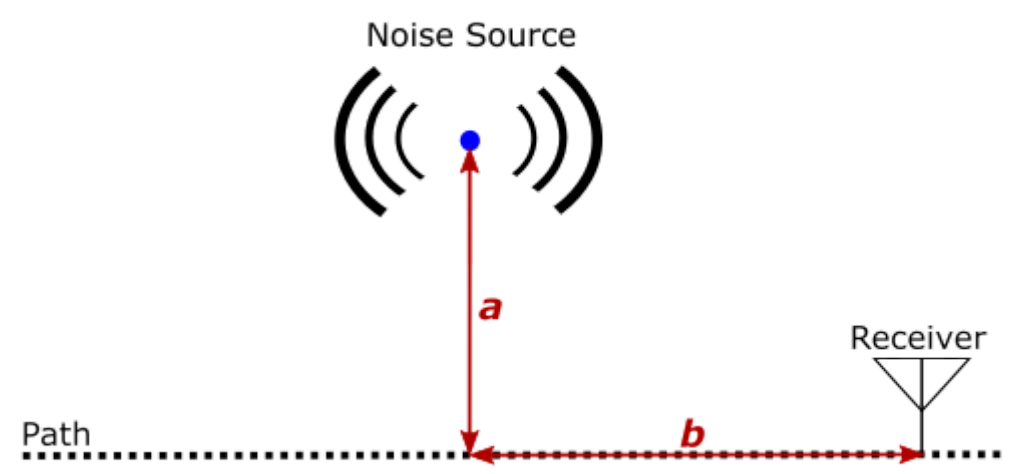

Figure 6. Modified power law model diagram showing distances $a$ and $b$.

As shown in Figure 7 and Figure 8, a simple power law model based on spherical spreading is effective for describing the shape and power decay for many of our high-powered regions. This indicates that the regions behave as isotropic, point-source noise emitters and suggests that typical high-powered noise sources encountered in the urban environment do not have elongated or irregular emission patterns (such as an exposed power line or a long fluorescent-lit sign). At $142 \mathrm{MHz}$, the average value of $a$ is $12.7 \mathrm{~m}$ whereas at $246.5 \mathrm{MHz}$, the average value is $7.9 \mathrm{~m}$. Source offset values in this range are physically plausible assuming that our point sources are located on or inside of buildings located along the sides of a typical $15 \mathrm{~m}$ wide street. Point-like sources at higher frequencies appear to be more spatially compact than those at lower frequencies. It is unclear at this stage whether this is attributable to differences in attenuation or the characteristics of the noise radiating devices themselves.

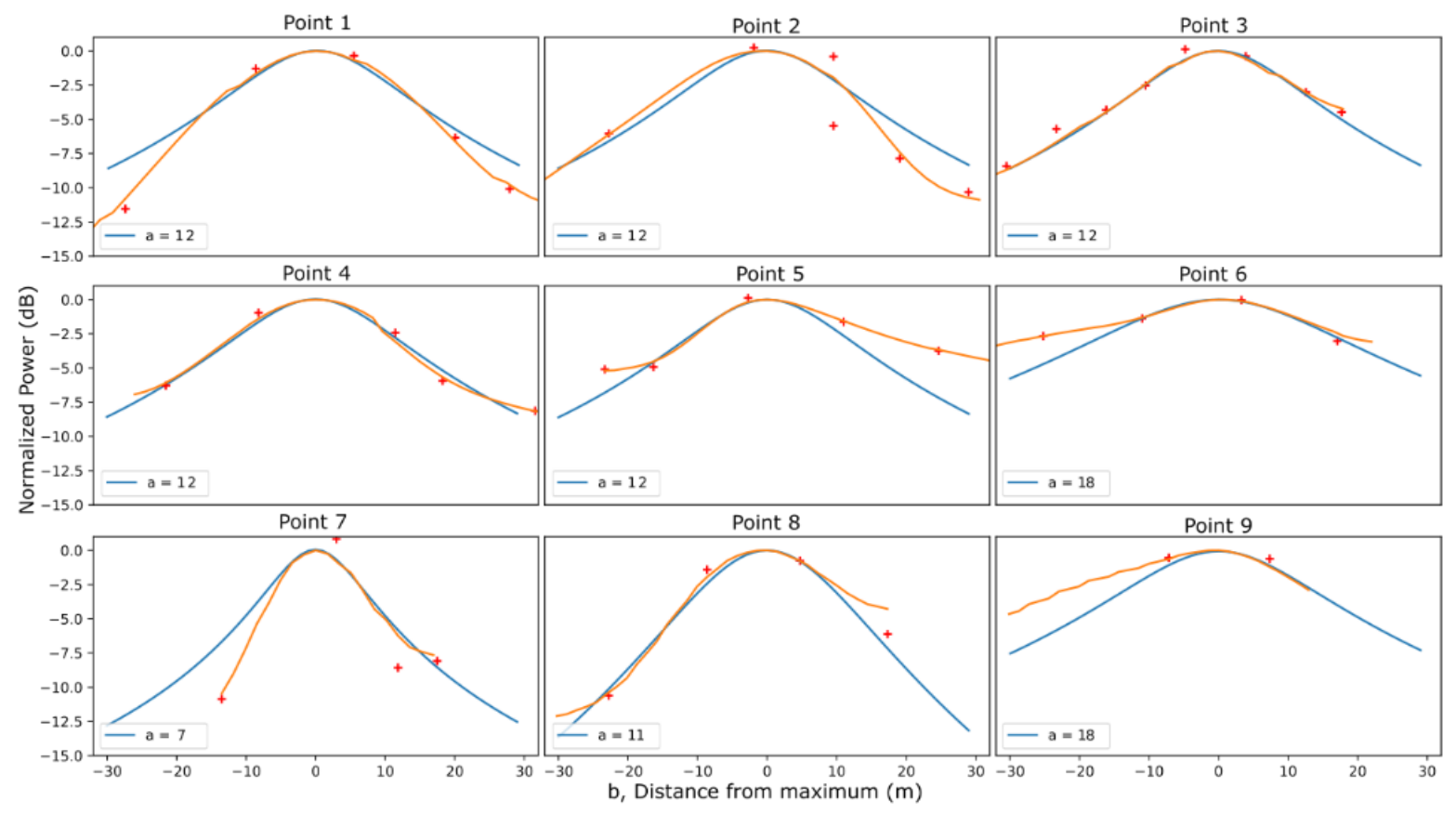

Figure 7. Modeled power law curves (blue) fit to profiles extracted from the isarithmic map over high powered regions (orange) at $142 \mathrm{MHz}$. Red crosses are data points collected near the profile line. Point locations are labeled in Figure 4. 
Based on these results, it is tempting to try to identify the exact sources for the high-powered noise regions. This is a difficult task with publically available data, especially since the sources are likely unintentional and undocumented byproducts of electronic systems. However, our results show that one can expect to encounter these high-powered areas, especially when surrounded by buildings (i.e. not in parks or other open spaces) and our values of $a$ provide the typical shape and power decay rates around these high-powered areas.

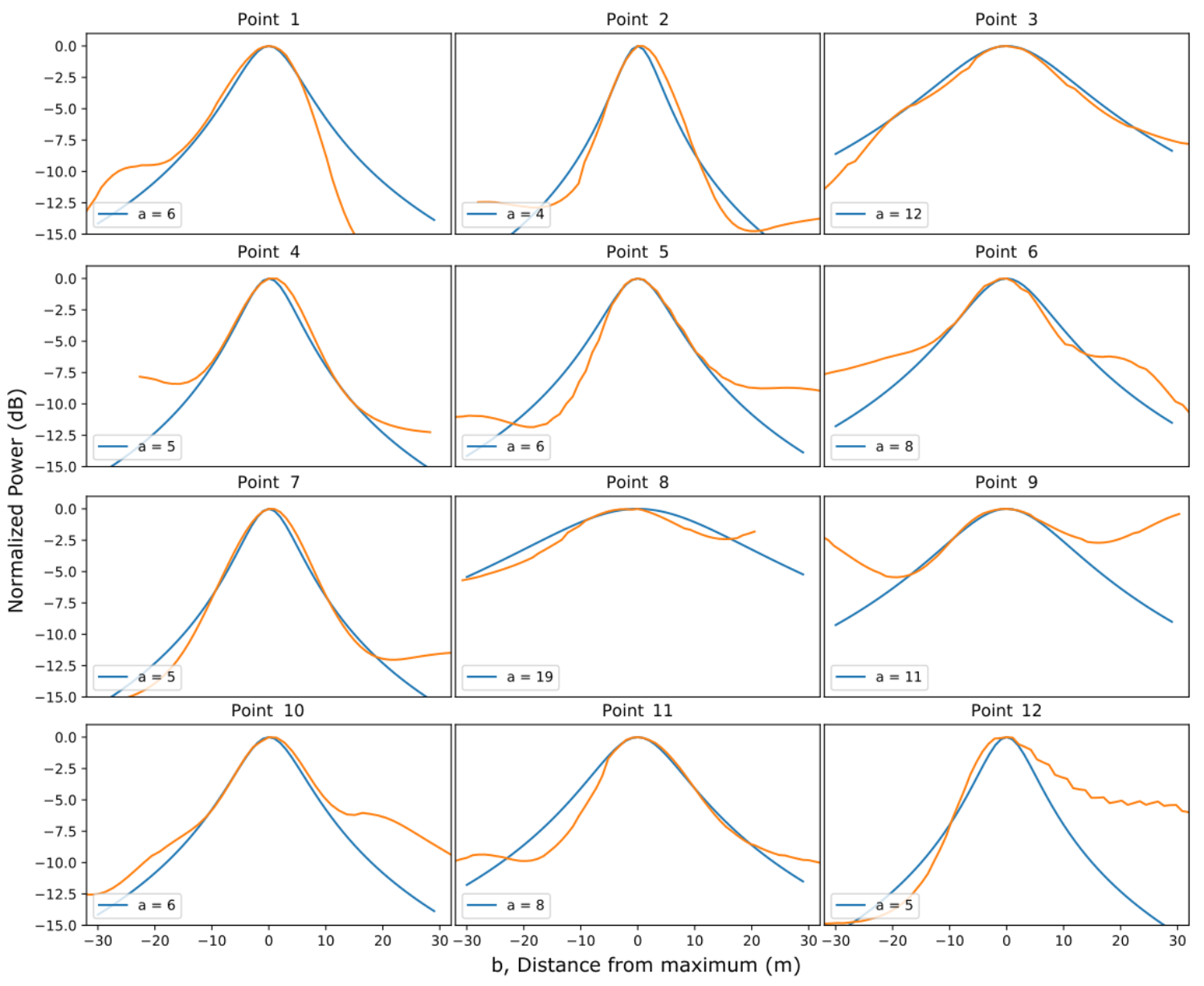

Figure 8. Modeled power law curves (blue) fit to profiles extracted from the isarithmic map over high powered regions (orange) at $246.5 \mathrm{MHz}$. Point locations are labeled in Figure 4.

In summary, our isarithmic maps are consistent with our previous work (Haedrich \& Breton, 2019) and show that VHF radio-frequency noise is highly variable, with median values varying on the order of 30 $\mathrm{dB}$ with a single block, in downtown Boston. We found parks and open areas to have the lowest values while streets surrounded by buildings have the highest values. Our results also suggest that Boston's downtown can be divided into three region-types: areas dominated by high-powered point-sources, areas with distributed low-power noise sources and open areas with few sources. High-powered regions appear to centrally symmetric and thus can be effectively modeled with a simple power law model. This work could be expanded upon by conducting surveys in other cities and further generalizing the urban noise field to help soldiers, first responders and other users of the radio-frequency spectrum predict system performance. Results of our work could also be used to develop realistic synthetic urban noise environments for training purposes. 


\subsection{Acknowledgements}

The authors would like to thank Sarah Gage for her efforts in the field and Jeffery A. Wepman of the Institute of Telecommunications Sciences for his advice and guidance on best practices for measuring noise. Funding provided by the US Army Basic Research Program. Permission to publish granted by Director, Cold Regions Research and Engineering Laboratory.

\subsection{References}

Achatz, R. J., \& Dalke, R. A. (2001). Man-Made Noise Power Measurements at VHF and UHF Frequencies. Tech. rep., U.S. Dept. Commerce.

Achatz, R., Lo, Y., Papazian, P., Dalke, R., \& Hufford, G. (1998). Man-made noise in the 136 to 138 MHz VHF meteorological satellite band. Tech. rep., National Telecommunications and Information Administration.

Bertoni, H. L. (2000). Radio Propagation for Modern Wireless Systems. Upper Saddle River, NJ: Prentice Hall PTR.

Boston Transportation Department. (2013). Lane Widths Chart. Retrieved from Boston Complete Streets: https://bostoncompletestreets.org/pdf/2013/LaneWidths_Chart.pdf

Buehler, W. E., King, C. H., \& Lunden, C. D. (1968). VHF city noise. Electromagnetic Compatibility Symposium Record (pp. 113-118). IEEE.

Cudak, M. C., Swenson, G. W., \& Cochran, W. W. (1991). Airborne measurements of incidental radio noise from cities. Radio Science, 26, 773-781.

Dalke, R., Achatz, R., Lo, Y., Papazian, P., \& Hufford, G. (1997). Measurement and analysis of manmade noise in VHF and UHF bands. Wireless Communications Conference, 1997., Proceedings (pp. 229-233). IEEE.

Esposito, R., \& Buck, R. (1973). A mobile wide-band measurement system for urban man-made noise. IEEE Transactions on Communications, 21, 1224-1232.

Fockens, T., Zwamborn, A., \& Leferink, F. (2019). Measurement Methodology and Results of Measurements of the Man-Made Noise Floor on HF in The Netherlands. IEEE Transaction on Electromagnetic Compatibility, 61(2), 337-343. doi:10.1109/TEMC.2018.2830512

GRASS Development Team. (2019). GRASS GIS manual: v.surf.bspline. (Open Source Geospatial Foundation) Retrieved from Geographic Resources Analysis Support System (GRASS GIS) Software Manual, Version 7.4: https://grass.osgeo.org/grass74/manuals/v.surf.bspline.html

Haedrich, C. E., \& Breton, D. J. (2019). Measuring Very High Frequency and Ultrahigh Frequency Radio Noise in Urban Environments: A Mobile Measurement System for Radio-Frequency Noise. Report ERDC/CRREL TR-19-8. Hanover, NH: Cold Regions Research and Engineering Laboratory. doi:http://dx.doi.org/10.21079/11681/33290

Herman, J. R. (1969). Survey of man-made radio noise. Progress in Radio Science, 1, 315-347.

ITU. (2016). Radio Noise. Recommendation, Internation Telecommunications Union, Radiocommunications Sector, Geneva.

Keysight Technologies. (2018, June 29). Noise Figure Measurement Accuracy: The Y-Factor Method. 
Retrieved from Keysight Technologies Online:

http://literature.cdn.keysight.com/litweb/pdf/5952-3706E.pdf

Lauber, W. R., \& Bertrand, J. M. (1977). Preliminary Urban VHF/UHF Radio Noise Intensity Measurements in Ottawa, Canada. Second Symposium and Technical Exhibition on Electromagnetic Compatibility. Montreaux.

Leferink, F., Silva, F., Catrysse, J., Batterman, S., Beauvois, V., \& Roc'h, A. (2010). Man-Made Noise in Our Living Environments. Radio Science Bulletin, 334, 49-57.

Middleton, D. (1973). Man-made noise in urban environments and transportation systems: Models and measurements. IEEE Transactions on Communications, 21, 1232-1241.

Oranc, H. S. (1975). Ignition noise measurements in the VHF/UHF bands. IEEE Transactions on Electromagnetic Compatibility, 2, 54-64.

Parsons, J. D., \& Sheikh, A. U. (1981). The magnitude of urban and suburban vhf man-made radio noise. Radio and Electronic Engineer, 51, 591-597.

Paulson, A. (2019). Precision Geolocation of Propagation Data Using GPS and Data Fusion. Proceedings of the 2019 IEEE International Symposium on Electromagnetic Compatibility, Signal and Power Integrity.

Rappaport, T. S. (2002). Wireless Communications: Principles and Practice. Upper Saddle River, NJ: Prentice-Hall, Inc.

Roy, T. N. (1981). Airborne man-made radio noise assessment. Tech. rep., Naval Ocean Systems Center.

Shepherd, R. A. (1973). Measurements of amplitude probability distributions and power of automobile ignition noise at HF. Tech. rep., Stanford Research Institute.

Skomal, E. N. (1965). Distribution and frequency dependence of unintentionally generated man-made VHF/UHF noise in metropolitan areas. IEEE Transactions on Electromagnetic Compatibility, 7, 263-278.

Skomal, E. N. (1969). Analysis of Airborne VHF/UHF Incidental Noise over MetropolItan Areas. IEEE Transactions on Electromagnetic Compatibility, EMC-11, 76-83.

Skomal, E. N. (1970). The range and frequency dependence of VHF-UHF man-made radio noise in and above metropolitan areas. IEEE Transactions on Vehicular Technology, 19, 213-221.

Skomal, E. N. (1973). An analysis of metropolitan incidental radio noise data. IEEE Transactions on Electromagnetic Compatibility, 45-57.

Spaulding, A. D., \& Disney, R. T. (1974). Man-made radio noise, part 1: Estimates for business, residential, and rural areas. OT Report, U.S. Dept. Commerce, Office of Telecommunications.

Spaulding, A., Ahlbeck, W., \& Espeland, L. (1971). Urban Residential man-made Radio Noise Analysis and Predictions. Institute for Telecommunication Sciences.

Wagstaff, A., \& Merricks, N. (2005). Man-made noise measurement programme. IEEE Proceedings Communications, 152, 371-377.

Wepman, J. A., \& Sanders, G. A. (2011). Wideband Man-Made Radio Noise Measurements in the VHF and low UHF Bands. Tech. rep., National Telecommunications and Information Administration. 


\section{REPORT DOCUMENTATION PAGE}

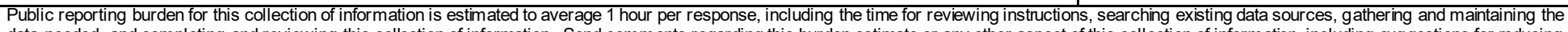

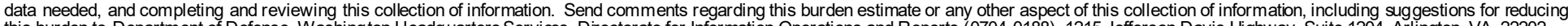

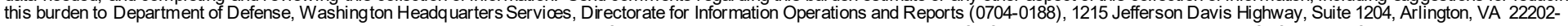

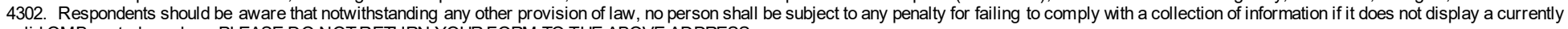
valid OMB control number. PLEASE DO NOT RETURN YOUR FORM TO THE ABOVE ADDRESS.
1. REPORT DATE
August 2020
2. REPORT TYPE
Final

4. TITLE AND SUBTITLE

3. DATES COVERED (From - To)

5a. CONTRACT NUMBER

Isa rithmic mapping of ra dio-frequency noise in the urban environment

5b. GRANT NUMBER

5c. PROGRAM ELEMENT NUMBER

$0611102 \mathrm{~T}$

6. AUTHOR(S)

5d. PROJECT NUMBER

T442

Caitlin E.Ha edrich, Da nielJ. Breton, D. Keith Wilson

5e. TASK NUMBER

01

5f. WORK UNIT NUMBER

7. PERFORMING ORGANIZATION NAME(S) AND ADDRESS(ES)

U.S. Army Engineer Research and Development Center

8. PERFORMING ORGANIZATION REPORT NUMBER

Cold Regions Research and Engineering Laboratory

72 Lyme Road

ERDC/CRREL MP-20-12

Ha nover, NH 03755

9. SPONSORING / MONITORING AGENCY NAME(S) AND ADDRESS(ES)

10. SPONSOR/MONITOR'S ACRONYM(S)

U.S. Army Corps of Engineers

Washington, DC 20314-1000

USACE

11. SPONSOR/MONITOR'S REPORT NUMBER(S)

\section{DISTRIBUTION / AVAILABILITY STATEMENT}

Approved for public release; distribution is unlimited.

\section{SUPPLEMENTARY NOTES}

Originally published in proceedings of the Military Sensing Symposium 2019, held February 25 - 28, 2019 in Orla ndo, FL. Funding was provided by the US Army Basic Research Program.

\section{ABSTRACT}

Radio-frequency (RF) background noise is a spatially-varying and critical parameter for predicting ra dio communication system and electromagnetic sensor performance in urban environments. Previous studies havem easured urban RF noise atfixed, representative loca tions. The Cold Regions Research and Engineering La boratory(CRREL) has developed a tunable system for conducting mobile RF noise mea surements in the VHF and UHF and shown that urban RF noise characteristics vary significa ntly and repeatably at a scale of tens of meters (Haedrich \& Breton, 2019). CRREL also found high-powered regions in Boston, MA that a re persistent over time. However, since previous studies conducted stationary measurements or measurements along linear transects, little is known about the 2-dim ensional topography of urban noise and the spatial distribution and characteristics of these high-powered regions. In this paper, we present the results of a dense, block-grid survey of downtown Boston, MA at 142 and 246.5 MHzwith measurements taken every meter a long ea ch street. We present isarithmic maps of median noise power and describethe spatial distribution, shape and other characteristics of the high-powered regions. We compare the ra te of noise power decay around high-powered regions to losses predicted by a power law model of path loss.

\section{SUBJECT TERMS}

Cities and towns, Radio frequency, Radio measurements, Noise

\begin{tabular}{|c|c|c|c|c|c|}
\hline 16. SECURITY CL & IFICATION OF: & & 17. LIMITATION & 18. NUMBER & 19a. NAME OF RESPONSIBLE PERSON \\
\hline $\begin{array}{l}\text { a. REPORT } \\
\text { Uncla ssified }\end{array}$ & $\begin{array}{l}\text { b. ABSTRACT } \\
\text { Uncla ssified }\end{array}$ & $\begin{array}{l}\text { c. THIS PAGE } \\
\text { Unclassified }\end{array}$ & UU & 16 & $\begin{array}{l}\text { 19b. TELEPHONE NUMBER } \\
\text { (include area code) }\end{array}$ \\
\hline
\end{tabular}

